\title{
113
}

\section{Nitrate and Phosphate Toxicity on Post Larvae of the Giant Fresh Water Prawn (Macrobrachium rosenbergii): Individual and Synergistic Effects}

\author{
Thenuwara T.T.K. ${ }^{1}$, Wijesinghe M.R. ${ }^{*}$, De Silva D.N. ${ }^{1}$ and Wijesekara R.D. ${ }^{2}$ \\ ${ }^{1}$ Department of Zoology, University of Colombo, Colombo 03, Sri Lanka \\ ${ }^{2}$ Department of Chemistry, University of Colombo, Colombo 03, Sri Lanka \\ *mayuri@zoology.cmb.ac.lk
}

\begin{abstract}
The indiscriminate use of fertilizers has resulted in nutrient enrichment giving rise to eutrophic conditions in many freshwater bodies in Sri Lanka. Few studies have investigated effects of field levels of nitrate and phosphate on commercial freshwater species. The present study therefore attempted to assess the individual and synergistic effects of nitrate and phosphate on post larvae of the Giant fresh Water Prawn Macrobrachium rosenbergii, which are released in large quantities into reservoir systems of the dry zone of Sri Lanka.

The post larvae were collected from a culture facility in Pambala, Chilaw, and were acclimatized. After the measurement of the initial body lengths the larvae were introduced into $500 \mathrm{ml}$ glass beakers $(\mathrm{n}=10$ per beaker) containing five field based concentrations of either nitrate $\left(0.01-100 \mathrm{mg} \mathrm{l}^{-1}\right)$ or phosphate $\left(0.001-10 \mathrm{mg} \mathrm{l}^{-1}\right)$. Controls and treatments were maintained in triplicate. Synergistic effects were also tested for $0.1 \mathrm{mg} \mathrm{l}^{-1}$ of phosphate with three concentrations of nitrate $\left(0.1,1,10 \mathrm{mg} \mathrm{l}^{-1}\right)$. Survival, growth and the feeding behaviour of the post larvae were monitored as end points of the empirical acute toxicity (96 hr) trials. Results revealed that both nitrate and phosphate enhances mortality levels in prawn larvae when acting alone at concentrations of $0.01 \mathrm{mg} \mathrm{l}^{-1}$ and above for nitrate and $0.001 \mathrm{mgl}^{-}$ ${ }^{1}$ and above for phosphate. For instance, mortality in controls was $13.3 \%$, and for the two nutrients at the lowest test levels i.e. $0.01 \mathrm{mg} \mathrm{l}^{-1}$ of nitrate and $0.001 \mathrm{mg} \mathrm{l}^{-1}$ of phosphate, were $23 \%$ and $20 \%$, respectively. The synergistic effects with both nitrate and phosphate were lower than the additive effects of each, at all tested levels, but were greater than the recorded individual effects. The synergistic mortality with $10 \mathrm{mg} \mathrm{l}^{-1}$ of nitrate and $0.1 \mathrm{mg} \mathrm{l}^{-1}$ of phosphate was greater than mortality induced by each nutrient acting alone. In contrast to mortality, effects on growth were not apparent with either nitrate or phosphate acting alone nor synergistically, while the phosphate alone and both nutrients acting synergistically, appeared to cause reduced feeding. These findings highlight the need for investigating effects of nutrient enrichment, and specifically their synergistic effects, on commercially exploited species in order to predict levels of sustainability of the inland fishery resources of Sri Lanka.
\end{abstract}

Keywords: Macrobrachium rosenbergii, Nitrates, Phosphates, Synergistic effects, Toxicity 